\title{
Original Article: Prognostic Factors of Long-Term Outcome and Functional Status Following Spontaneous Cerebellar Hemorrhage
}

\author{
Chia-Hung Sun, Shin-Tsu Chang, Liang-Cheng Chen, Heng-Yi Chu, \\ Shang-Lin Chiang, Tsung-Ying Li, Yung-Tsan Wu \\ Department of Physical Medicine and Rehabilitation, Tri-Service General Hospital, School of Medicine, National \\ Defense Medical Center, Taipei, Taiwan \\ Email: jim4882001@gmail.com
}

Received 26 January 2014; revised 2 March 2014; accepted 10 March 2014

Copyright (C) 2014 by authors and Scientific Research Publishing Inc.

This work is licensed under the Creative Commons Attribution International License (CC BY). http://creativecommons.org/licenses/by/4.0/

(c) (i) Open Access

\begin{abstract}
Cerebellar hemorrhage $(\mathrm{CH})$ has a higher early mortality rate compared with other types of intracranial hemorrhage and the survivors often suffer from momentous disability. Hence, the prognostic factors of long-term outcome beyond 6 months after $\mathrm{CH}$ are clinically valuable, however only three studies were reported in the literature. Sixty-one patients with $\mathrm{CH}$ were retrospectively analyzed at least 6 months after hemorrhage. The long-term outcome of all patients and long-term functional status of survivors beyond 6 months (the patients who died within 6 months after hemorrhage were excluded) were assessed using the modified Rankin Scale (mRS): favorable outcome (mRS 0 - 2) and unfavorable outcome (mRS 3 - 6). All of the prognostic factors were analyzed by univariate and multivariate Cox proportional hazards regression models. There were 16 (26.2\%) patients in the favorable outcome group and $45(73.8 \%)$ in the unfavorable outcome group with respect of long-term outcome in all patients. The radiological brainstem compression $(H R=3 ; p=0.015)$ was shown to be an independent predictor. On the other hand, 46 out of 61 (75.4\%) patients survived beyond 6 months. In total, $16(34.7 \%)$ patients had a favorable functional status, and $65.3 \%(30 / 46)$ had a persistent unfavorable functional status. Moreover, only age $\geq 65$ years $(H R=3 ; p=0.019)$ was an independent predictor. Radiological brainstem compression and age $\geq 65$ were respectively shown to be a strong prognostic factor for long-term outcome and functional status among survivors beyond 6 months after hemorrhage in patients with $\mathrm{CH}$.
\end{abstract}

\section{Keywords}

Prognostic Factor; Long-Term Outcome; Cerebellar Hemorrhage

How to cite this paper: Sun, C.-H., et al. (2014) Original Article: Prognostic Factors of Long-Term Outcome and Functional Status Following Spontaneous Cerebellar Hemorrhage. World Journal of Cardiovascular Diseases, 4, 93-98. 


\section{Introduction}

Cerebellar hemorrhage (CH) is the least common type of intracranial hemorrhage (ICH), accounting for only $10 \%$ of all ICH cases in western countries [1], rising to $20 \%-30 \%$ in the Taiwanese population [2], due to the higher prevalence of hypertension, which is reported to be a major risk of $\mathrm{CH}$ [3] [4]. $\mathrm{CH}$ is regarded as a predictive factor of outcome following ICH because of the high risk of brainstem compression [4]. As well as a higher early mortality rate (20\% to $75 \%)$ compared with other types of ICH (30\% - 50\%) [1] [3], survivors of the acute phase of $\mathrm{CH}$ often suffer from momentous disability [3] [5]. In previous studies of patients with $\mathrm{CH}$, the clinical outcome was mostly assessed at hospital discharge, or within 3 months of hemorrhage [3] [5], with only three studies assessing outcomes beyond 6 months [6]-[8]. The lack of statistics regarding long-term outcomes in patients with $\mathrm{CH}$ hinders therapeutic decision making for survivors at the sub-acute and chronic stages. The purpose of this study was to survey the significant prognostic factors of this topic, and review the existing literature.

\section{Materials and Methods}

Sixty-one patients diagnosed with acute spontaneous $\mathrm{CH}$, without prior disability, were admitted to our hospital between 2004 and 2011, within 48 h of the onset of symptoms. None of the patients had suffered a prior stroke, or presented with complications associated with another hemorrhagic lesion or hemorrhagic transformation of ischemic stroke. On admission, all patients underwent detailed physical examination, routine laboratory testing, and imaging studies. The initial neurological state of all patients was evaluated using the Glasgow coma scale (GCS). Patients' blood glucose/sugar (BS), systolic blood pressure (SBP), diastolic blood pressure (DBP), heart rate (HR), and body temperature (BT) were measured immediately before they underwent computerized tomography. Basic characteristics, including age, gender, date of birth, and pre-existing or concomitant illnesses, were collected. Imaging findings, including the maximum diameter of hematoma, evidence of intraventricular hemorrhage (IVH), radiographic signs of brainstem compression (presence of obliterated basal cisterns), and hydrocephalus, were also obtained. Surgical decompression consisting of craniotomy, evacuation of hematoma, or ventricular drainage was performed (except for patients who had a large hemorrhage, or coma status without brainstem reflexes, due to its predictably poor outcome) [5] [9].

All the above information was acquired by the retrospective analysis of patient charts. Clinical data concerning long-term outcomes and functional status during the follow-up period were retrieved from medical records, or from a telephone interview with the patient, close relatives, or caregiver, conducted by the same physician. The long-term outcome and functional status were assessed using the modified Rankin Scale (mRS) [10]. The follow-up time was at least 6 months after hemorrhage, and endpoints were calculated from the onset of $\mathrm{CH}$ until data capture.

All patients were divided into 2 outcome groups: favorable outcome (mRS scale 0 - 2) and unfavorable outcome (mRS scale 3 - 6). The cut-off points of continuous variables were based on previously published cut-off values: age $\geq 65$ [11], BS levels $\geq 140 \mathrm{mg} / \mathrm{dl}$ [4] [12], maximum hematoma diameter $\geq 3 \mathrm{~cm}$ [4] [13], $\mathrm{SBP} \geq 200$ $\mathrm{mmHg}$ [4] [13], GCS scores $\leq 8$ [4] [14], HR $\geq 100$ beats/min [13], BT $\geq 37.5^{\circ} \mathrm{C}$ [4] [15], and $\mathrm{DBP} \geq 120 \mathrm{mmHg}$ [4] [16]. Variables showing $\mathrm{p}<0.05$ in the univariate analysis were incorporated into the multivariate analysis, which was performed using the enter regression method. The independent risk factors in the final model were presented as hazard ratios (HRs) with 95\% confidence intervals (CIs). The threshold for statistical significance was set at $\mathrm{p}<0.05$.

Results: Long-term outcome: Follow-up evaluation was completed for all 61 patients, and the mean follow-up time was $38.3 \pm 30.8$ months. The baseline characteristics of the study population are summarized in Table 1. The mean age of patients was $65.5 \pm 15.8$ years (standard deviation). In total, there were 16 (26.2\%) patients in the favorable outcome group (11 men, 5 women), and 45 (73.8\%) in the unfavorable outcome group (28 men, 17 women). The results from the univariate and multivariate enter Cox regression analyses for longterm outcome are shown in Table 2 . The following 4 risk factors were found to be significantly correlated with long-term outcome in the univariate analysis: GCS scores $\leq 8$ (HR $=3.4 ; \mathrm{p}<0.001$ ), initial BS levels $\geq 140$ $\mathrm{mg} / \mathrm{dl}(\mathrm{HR}=2.8 ; \mathrm{p}=0.002)$, maximum hematoma diameter $\geq 3 \mathrm{~cm}(\mathrm{HR}=3.2 ; \mathrm{p}=0.001)$, radiological brainstem compression $(\mathrm{HR}=6.1 ; \mathrm{p}<0.001)$.

Long-term functional status of survivors: Of these 61 patients, 15 patients (24.6\%) died during hospitalization, and 46 patients (75.4\%) survived after discharge. No patients died during the follow-up period of at least 6 months after hemorrhage. In total, 16 out of 46 patients (34.7\%) had a favorable functional status, and 65.3\% 
Table 1. The baseline characteristics of the study population affecting long-term functional status in all patients and survivors at least 6 months after hemorrhage.

\begin{tabular}{|c|c|c|c|c|c|c|}
\hline \multirow{2}{*}{ Variable } & \multicolumn{3}{|c|}{ Long-term outcome of all patients } & \multicolumn{3}{|c|}{ Long-term outcome of survivors } \\
\hline & $\begin{array}{l}\text { All patients } \\
\quad(\mathrm{n}=61)\end{array}$ & $\begin{array}{l}\text { Favorable outcome } \\
(\mathrm{mRS} 0 \text { - 2) }(\mathrm{n}=16)\end{array}$ & $\begin{array}{l}\text { Unfavorable outcome } \\
(\mathrm{mRS} 3-6)(n=45)\end{array}$ & $\begin{array}{l}\text { Survivors } \\
(\mathrm{n}=46)\end{array}$ & $\begin{array}{l}\text { Favorable outcome } \\
(\mathrm{mRS} 0 \text { - 2) }(\mathrm{n}=16)\end{array}$ & $\begin{array}{l}\text { Unfavorable outcome } \\
(\mathrm{mRS} 3-6)(\mathrm{n}=30)\end{array}$ \\
\hline Age (year) & $65.5 \pm 15.8$ & $56.0 \pm 15.3$ & $68.9 \pm 14.7$ & $66.4 \pm 15.2$ & $56.0 \pm 15.3$ & $72.0 \pm 12.0$ \\
\hline Initial GCS & $10.7 \pm 4.6$ & $13.9 \pm 2.2$ & $9.6 \pm 4.7$ & $12.6 \pm 3.4$ & $13.9 \pm 2.2$ & $11.9 \pm 3.7$ \\
\hline Initial SBP (mmHg) & $188.0 \pm 37.6$ & $180.3 \pm 27.1$ & $190.8 \pm 40.6$ & $182.2 \pm 34.2$ & $180.3 \pm 27.1$ & $183.3 \pm 37.9$ \\
\hline Initial DBP (mmHg) & $102.3 \pm 23.4$ & $104.3 \pm 13.8$ & $101.5 \pm 26.1$ & $101.3 \pm 21.4$ & $104.3 \pm 13.8$ & $99.7 \pm 24.6$ \\
\hline Initial HR (beat/min) & $88.4 \pm 17.7$ & $84.3 \pm 15.6$ & $89.8 \pm 18.4$ & $85.8 \pm 18.1$ & $84.3 \pm 15.6$ & $86.7 \pm 19.5$ \\
\hline Initial BT $\left({ }^{\circ} \mathrm{C}\right)$ & $36.3 \pm 0.8$ & $37.0 \pm 0.6$ & $36.0 \pm 0.8$ & $36.4 \pm 0.7$ & $37.0 \pm 0.6$ & $36.1 \pm 0.7$ \\
\hline $\begin{array}{l}\text { Maximum diameter } \\
(\mathrm{cm})\end{array}$ & $3.8 \pm 1.5$ & $2.7 \pm 1.3$ & $4.2 \pm 1.5$ & $3.3 \pm 1.4$ & $2.7 \pm 1.3$ & $3.61 \pm 1.4$ \\
\hline Initial BS & $165.6 \pm 56.4$ & $133.0 \pm 26.3$ & $177.2 \pm 59.8$ & $153.5 \pm 48.2$ & $133.0 \pm 26.3$ & $164.4 \pm 53.7$ \\
\hline
\end{tabular}

Note: GCS = Glasgow Coma Scale, SBP = systolic blood pressure, DBP = diastolic blood pressure, HR = heart rate, BT = body temperature, BS = blood glucose/sugar, IVH = intraventricular hemorrhage Variables associated with p value $<0.05$ on univariate analysis were incorporated in the multivariate analysis which was performed by enter Cox regression model. The independent risk factors in the final model were presented as hazard ratios, including 95\% confidence intervals (CI).

(30/46) had a persistent unfavorable functional status at the 6-month follow up. Table 1 summarizes their baseline characteristics. The mean age of the patients was $66.4 \pm 15.2$ years, and age in the unfavorable outcome group was greater than in the favorable outcome group ( $72.0 \pm 12.0$ years vs. $56.0 \pm 15.3$ years). The results from the univariate and multivariate enter Cox regression analyses are shown in Table 3.

\section{Discussion}

Our study showed that radiological brainstem compression $(\mathrm{HR}=3)$ was a strong predictor of long-term outcome at least 6 months after hemorrhage in patients with $\mathrm{CH}$. Moreover, an age $\geq 65$ years was the single independent predictor $(\mathrm{HR}=3)$ of long-term functional status in survivors beyond 6 months after $\mathrm{CH}$. To the best of our knowledge, this is the first study of this topic in Taiwanese population.

Only three studies have been published concerning the predictors of long-term outcome and functional status more than 6 months after $\mathrm{CH}$ [6]-[8]. Dolderer et al. [6] followed 75 patients with $\mathrm{CH}$ (mean follow up period, $49 \pm 34$ months) and found that only 32\% achieved a favorable outcome (mRS $0-2$ ). The unfavorable outcome group (68\%) had a mortality rate of $48 \%$ (36 out of 75 patients), and $61.5 \%$ of survivors (24/39) achieved a favorable outcome. They revealed that factors associated with unfavorable long-term outcome were decreased consciousness level, clinical signs of brainstem compression, hydrocephalus, intubation, and surgical intervention. Dammann and colleagues [7] followed 57 surgically treated patients with $\mathrm{CH}$ for at least 12 months (mean follow-up time, 34 months). In total, 27 out of 57 patients (47.3\%) had a favorable outcome, defined according to the Glasgow outcome scale (4 - 5); 16 patients (27.7\%) had a persistent unfavorable functional outcome, and 14 patients died (25\%). Of the survivors, $62.7 \%$ achieved a favorable outcome. The initial neurological condition, level of consciousness, radiological brainstem compression, and a tight posterior fossa were predictive of long- term poor clinical outcome. Pong et al. [8] followed 72 Chinese patients with $\mathrm{CH}$, of which 12 patients died within 30 days (16.7\%), 26 (36.1\%) achieved a favorable functional status, and $47.2 \%$ had an unfavorable functional status. $43.3 \%$ of survivors had reached a favorable outcome at 6 months after $\mathrm{CH}$. After excluding patients dying within 30 days, age $\geq 75$ was shown to be an independent predictor of functional status at 6 months. The results of the current study are in accordance with these previous findings.

Brainstem compression by cerebellar hematoma is a specific and severe complication of $\mathrm{CH}$ as compared with other types of ICH, and may contribute significantly to neurological deterioration, impaired consciousness, and death [17]. Notably, the mortality rate was highest within the first 3 months after $\mathrm{CH}$, so it is not surprising that radiological brainstem compression was a strong prognostic factor for long-term outcome in the present study. Indeed, radiological brainstem compression was also found to be predictive of first-week mortality [18], 
Table 2. The Cox regression analysis of the study population affecting long-term outcome of all patients.

\begin{tabular}{|c|c|c|c|c|c|c|c|}
\hline \multirow{2}{*}{ Variable } & \multirow{2}{*}{$\begin{array}{l}\text { All patients } \\
\quad(\mathrm{n}=61)\end{array}$} & \multirow{2}{*}{\multicolumn{2}{|c|}{$\begin{array}{l}\text { Favorable outcome Unfavorable outcome } \\
(\mathrm{mRS} 0-2)(\mathrm{n}=16)(\mathrm{mRS} 3-6)(\mathrm{n}=45)\end{array}$}} & \multicolumn{2}{|c|}{ Univariate analysis } & \multicolumn{2}{|c|}{ Multivariate analysis } \\
\hline & & & & $\begin{array}{l}\text { Hazard ratio } \\
\text { (95\% CI.) }\end{array}$ & $p$ value & $\begin{array}{c}\text { Hazard ratio } \\
\text { (95\% CI.) }\end{array}$ & $p$ value \\
\hline Surgical decompression & $32.0(52.5)$ & $9.0(56.3)$ & $23.0(51.1)$ & $0.8(0.4-1.4)$ & 0.354 & & \\
\hline Male sex, $n(\%)$ & $39.0(63.9)$ & $11.0(68.8)$ & $28.0(62.2)$ & $1.1(0.6-2.0)$ & 0.874 & & \\
\hline Age (year) $\geq 65$ & $37.0(60.7)$ & $5.0(31.3)$ & $32.0(71.1)$ & $1.6(0.8-3.0)$ & 0.165 & & \\
\hline Smoking, $n$ (\%) & $29.0(47.5)$ & $9.0(56.3)$ & $20.0(44.4)$ & $0.8(0.4-1.5)$ & 0.467 & & \\
\hline Drinking, $n(\%)$ & $22.0(36.7)$ & $5.0(33.3)$ & $17.0(37.8)$ & $1.3(0.7-2.5)$ & 0.342 & & \\
\hline \multicolumn{8}{|l|}{ Past medical history } \\
\hline Hypertension, $n$ (\%) & $42.0(68.9)$ & $11.0(68.8)$ & $31.0(68.9)$ & $0.9(0.5-1.7)$ & 0.733 & & \\
\hline Diabetes mellitus, $n$ (\%) & $17.0(27.9)$ & $3.0(18.8)$ & $14.0(31.1)$ & $1.2(0.7-2.4)$ & 0.500 & & \\
\hline Coronary artery disease, $n(\%)$ & $19.0(31.1)$ & $2.0(12.5)$ & $17.0(37.8)$ & $1.5(0.8-2.7)$ & 0.202 & & \\
\hline Dyslipidemia, $n$ (\%) & $2.0(3.3)$ & $1.0(6.3)$ & $1.0(2.2)$ & $0.6(0.1-4.2)$ & 0.582 & & \\
\hline Coagulopathy, $n$ (\%) & $7.0(11.5)$ & $1.0(6.3)$ & $6.0(13.3)$ & $2.4(1.0-5.7)$ & 0.059 & & \\
\hline \multicolumn{8}{|l|}{ Clinical parameters } \\
\hline Initial GCS $\leq 8$ & $21.0(34.4)$ & $1.0(6.3)$ & $20.0(44.4)$ & $3.4(1.8-6.3)$ & $0.000^{* *}$ & & \\
\hline Initial SBP (mmHg) $\geq 200$ & $21.0(34.4)$ & $3.0(18.8)$ & $18.0(40.0)$ & $1.4(0.8-2.6)$ & 0.259 & & \\
\hline Initial DBP $(\mathrm{mmHg}) \geq 120$ & $13.0(21.3)$ & $3.0(18.8)$ & $10.0(22.2)$ & $1.3(0.7-2.7)$ & 0.429 & & \\
\hline Initial HR (beat/min) $\geq 100$ & $19.0(31.1)$ & $4.0(25.0)$ & $15.0(33.3)$ & $1.4(0.7-2.6)$ & 0.313 & & \\
\hline Initial $\mathrm{BT}\left({ }^{\circ} \mathrm{C}\right) \geq 37.5^{\circ} \mathrm{C}$ & $3.0(4.9)$ & $3.0(18.8)$ & $0(0)$ & $0(0-4.9)$ & 0.192 & & \\
\hline Initial $\mathrm{BS} \geq 140$ & $35.0(57.4)$ & $4.0(25.0)$ & $31.0(68.9)$ & $2.8(1.5-5.3)$ & $0.002^{* *}$ & & \\
\hline \multicolumn{8}{|l|}{ Radiological parameters } \\
\hline Maximum diameter $(\mathrm{cm}) \geq 3$ & $35.0(57.4)$ & $4.0(25.0)$ & $31.0(68.9)$ & $3.2(1.7-6.3)$ & $0.001^{* *}$ & & \\
\hline Hydrocephalus, $n$ (\%) & $42.0(68.9)$ & $10.0(62.5)$ & $32.0(71.1)$ & $1.4(0.7-2.6)$ & 0.348 & & \\
\hline Brainstem compression, $n(\%)$ & $18.0(29.5)$ & $1.0(6.3)$ & $17.0(37.8)$ & $6.1(2.9-12.8)$ & $0.000^{* *}$ & $3(1.2-7.3)$ & $0.015^{*}$ \\
\hline IVH, $n(\%)$ & 39.0 (63.9) & $9.0(56.3)$ & $30.0(66.7)$ & $1.5(0.8-2.8)$ & 0.197 & & \\
\hline
\end{tabular}

Note: 1. GCS = Glasgow Coma Scale, SBP = systolic blood pressure, DBP = diastolic blood pressure, $\mathrm{HR}=$ heart rate, $\mathrm{BT}=$ body temperature, BS = blood glucose/sugar, IVH = intraventricular hemorrhage 2. Variables associated with p value $<0.05$ on univariate analysis were incorporated in the multivariate analysis which was performed by enter Cox regression model. The independent risk factors in the final model were presented as hazard ratios, including $95 \%$ confidence intervals (CI). $3 .{ }^{* *} \mathrm{p} \leqq 0.01,{ }^{*} \mathrm{p} \leqq 0.05$.

short-term neurological deterioration, and poor outcome [13].

Several retrospective studies have analyzed the clinical and imaging features associated with, or predictive of, poor outcome at discharge or within 3 months of $\mathrm{CH}$ : increased hematoma size was strongly correlated with poor outcome [4] [5]; GCS $\leq 8$ was a significant predictor of death [8] [14] [18]; a maximum hematoma diameter $\geq 3 \mathrm{~cm}$ was predictive of neurological deterioration and poor outcome [4] [13] [14]. The imaging features indicative of a poor prognosis were the presence of IVH [4] [6], hydrocephalus [4] [19], and visible brainstem compression [4] [6] [7] [18]. Moreover, when patients dying in the acute stage of $\mathrm{CH}$ were excluded, age become the only prognostic factor of long-term functional status, both in our study, and in recent research [8].

\section{Conclusion}

In conclusion, radiological brainstem compression was shown to be a strong prognostic factor for long-term 
Table 3. The Cox regression analysis of the study population affecting long-term functional status in patients surviving at least 6 month after hemorrhage.

\begin{tabular}{|c|c|c|c|c|c|c|c|}
\hline \multirow[b]{2}{*}{ Variable } & \multirow{2}{*}{$\begin{array}{l}\text { All patients } \\
\quad(n=46)\end{array}$} & \multirow{2}{*}{$\begin{array}{l}\text { Favorable outcome } \\
(\mathrm{mRS} 0-2)(\mathrm{n}=16)\end{array}$} & \multirow{2}{*}{$\begin{array}{l}\text { Unfavorable outcome } \\
(\mathrm{mRS} 3-6)(\mathrm{n}=30)\end{array}$} & \multicolumn{2}{|c|}{ Univariate analysis } & \multicolumn{2}{|c|}{ Multivariate analysis } \\
\hline & & & & $\begin{array}{c}\text { Hazard ratio } \\
\text { (95\% CI.) }\end{array}$ & $p$ value & $\begin{array}{c}\text { Hazard ratio } \\
\text { (95\% CI.) }\end{array}$ & $p$ value \\
\hline Surgical decompression & $28.0(60.9)$ & $9.0(56.3)$ & $19.0(63.3)$ & $1.1(0.5-2.4)$ & 0.766 & & \\
\hline Male sex, $n(\%)$ & $30.0(65.2)$ & $11.0(68.8)$ & $19.0(63.3)$ & $1.2(0.5-2.6)$ & 0.676 & & \\
\hline Age (year) $\geq 65$ & $29.0(63.0)$ & $5.0(31.3)$ & $24.0(80.0)$ & $2.6(1.0-6.3)$ & $0.040^{*}$ & $3.0(1.2-7.6)$ & $0.019^{*}$ \\
\hline Smoking, $n(\%)$ & $20.0(43.5)$ & $9.0(56.3)$ & $11.0(36.7)$ & $0.5(0.3-1.2)$ & 0.116 & & \\
\hline Drinking, $n(\%)$ & $14.0(31.1)$ & $5.0(33.3)$ & $9.0(30.0)$ & $1.1(0.5-2.4)$ & 0.843 & & \\
\hline \multicolumn{8}{|l|}{ Past medical history } \\
\hline Hypertension, $n$ (\%) & $33.0(71.7)$ & $11.0(68.8)$ & $22.0(73.3)$ & $1.0(0.5-2.4)$ & 0.912 & & \\
\hline Diabetes mellitus, $n(\%)$ & $12.0(26.1)$ & $3.0(18.8)$ & $9.0(30.0)$ & $1.2(0.6-2.7)$ & 0.617 & & \\
\hline Coronary artery disease, $n$ (\%) & 12.0 & $2.0(12.5)$ & $10.0(33.3)$ & $1.3(0.6-2.8)$ & 0.510 & & \\
\hline Dyslipidemia, $n$ (\%) & $2.0(4.3)$ & $1.0(6.3)$ & $1.0(3.3)$ & $0.8(0.1-5.9)$ & 0.830 & & \\
\hline Coagulopathy, $n(\%)$ & $3.0(6.5)$ & $1.0(6.3)$ & $2.0(6.7)$ & $1.9(0.4-8.2)$ & 0.380 & & \\
\hline \multicolumn{8}{|l|}{ Clinical parameters } \\
\hline Initial GCS $\leq 8$ & $7.0(15.2)$ & $1.0(6.3)$ & $6.0(20.0)$ & $1.6(0.7-4.0)$ & 0.303 & & \\
\hline Initial SBP $(\mathrm{mmHg}) \geq 200$ & $14.0(30.4)$ & $3.0(18.8)$ & $11.0(36.7)$ & $1.3(0.6-2.7)$ & 0.490 & & \\
\hline Initial DBP $(\mathrm{mmHg}) \geq 120$ & $9.0(19.6)$ & $3.0(18.8)$ & $6.0(20.0)$ & $1.3(0.5-3.3)$ & 0.536 & & \\
\hline Initial HR (beat/min) $\geq 100$ & $12.0(26.1)$ & $4.0(25.0)$ & $8.0(26.7)$ & $1.1(0.5-2.6)$ & 0.766 & & \\
\hline Initial BT $\left({ }^{\circ} \mathrm{C}\right) \geq 37.5^{\circ} \mathrm{C}$ & $3.0(6.5)$ & $3.0(18.8)$ & $0(0)$ & $0(0-8.5)$ & 0.241 & & \\
\hline Initial BS $\geq 140$ & $21.0(45.7)$ & $4.0(25.0)$ & $17.0(56.7)$ & $2.1(1.0-4.3)$ & $0.049^{*}$ & & \\
\hline \multicolumn{8}{|l|}{ Radiological parameters } \\
\hline Maximum diameter $(\mathrm{cm}) \geq 3$ & $20.0(43.5)$ & $4.0(25.0)$ & $16.0(53.3)$ & $2.2(1.0-4.5)$ & $0.039^{*}$ & & \\
\hline Hydrocephalus, $n$ (\%) & $27.0(58.7)$ & $10.0(62.5)$ & $17.0(56.7)$ & $0.8(0.4-1.7)$ & 0.555 & & \\
\hline Brainstem compression, $n$ (\%) & $5.0(10.9)$ & $1.0(6.3)$ & $4.0(13.3)$ & $3.6(1.2-11)$ & $0.022^{*}$ & & \\
\hline IVH, $n(\%)$ & $24.0(52.2)$ & $9.0(56.3)$ & $15.0(50.0)$ & $0.9(0.4-1.8)$ & 0.708 & & \\
\hline
\end{tabular}

Note: 1 . GCS = Glasgow Coma Scale, SBP = systolic blood pressure, DBP = diastolic blood pressure, $\mathrm{HR}=$ heart rate, $\mathrm{BT}=$ body temperature, $\mathrm{BS}=$ blood glucose/sugar, IVH = intraventricular hemorrhage 2. Variables associated with p value $<0.05$ on univariate analysis were incorporated in the multivariate analysis which was performed by enter Cox regression model. The independent risk factors in the final model were presented as hazard ratios, including 95\% confidence intervals (CI). 3. ${ }^{*} \mathrm{p} \leqq 0.05$. 4. Univariate analysis is the simplest form of quantitative (statistical) analysis. The analysis is carried out with the description of a single variable in terms of the applicable unit of analysis. Multivariate statistics is a form of statistics encompassing the simultaneous observation and analysis of more than one outcome variable. The application of multivariate statistics is multivariate analysis.

outcome after at least 6 months in patients with $\mathrm{CH}$. On the other hand, an age $\geq 65$ was an independent prognostic factor of long-term functional status among survivors beyond 6 months after hemorrhage. These findings may facilitate the identification of prognostic factors for long-term outcome after $\mathrm{CH}$, thereby aiding clinicians and patients in selecting treatment and management strategies.

\section{References}

[1] Kirollos, R.W., Tyagi, A.K., Ross, S.A., van Hille, P.T. and Marks, P.V. (2001) Management of Spontaneous Cerebellar Hematomas: A Prospective Treatment Protocol. Neurosurg, 49, 1378-1386. 
http://dx.doi.org/10.1097/00006123-200112000-00015

[2] Chen, Z.Y., Chang, S.F. and Su, C.L. (1995) Weather and Stroke in a Subtropical Area: Ilan, Taiwan. Stroke, 26, 569572. http://dx.doi.org/10.1161/01.STR.26.4.569

[3] Salvati, M., Cervoni, L., Raco, A. and Delfini, R. (2001) Spontaneous Cerebellar Hemorrhage: Clinical Remarks on 50 Cases. Surgical Neurology, 55, 156-161. http://dx.doi.org/10.1016/S0090-3019(01)00347-0

[4] Wu, Y.T., Li, T.Y., Lu, S., Chen, L.C., Chu, H.Y., Chiang, S.L., et al. (2012) Hyperglycemia as a Predictor of Poor Outcome at Discharge in Patients with Acute Spontaneous Cerebellar Hemorrhage. Cerebellum, 11, 543-548. http://dx.doi.org/10.1007/s12311-011-0317-7

[5] Kobayashi, S., Sato, A., Kageyama, Y., Nakamura, H., Watanabe, Y. and Yamaura, A. (1994) Treatment of Hypertensive Cerebellar Hemorrhage: Surgical or Conservative Management? Neurosurg, 34, 246-251. http://dx.doi.org/10.1227/00006123-199402000-00006

[6] Dolderer, S., Kallenberg, K., Aschoff, A., Schwab, S. and Schwarz, S. (2004) Long-Term Outcome after Spontaneous Cerebellar Haemorrhage. European Neurology, 52, 112-119. http://dx.doi.org/10.1159/000080268

[7] Dammann, P., Asgari, S., Bassiouni, H., Gasser, T., Panagiotopoulos, V., Gizewski, E.R., et al. (2011) Spontaneous Cerebellar Hemorrhage-Experience with 57 Surgically Treated Patients and Review of the Literature. Neurosurgical Review, 34, 77-86. http://dx.doi.org/10.1007/s10143-010-0279-0

[8] Pong, V., Chan, K.H., Chong, B.H., Lui, W.M., Leung, G.K., Tse, H.F., et al. (2012) Long-Term Outcome and Prognostic Factors after Spontaneous Cerebellar Hemorrhage. Cerebellum, 11, 939-945. http://dx.doi.org/10.1007/s12311-012-0371-9

[9] Heiskanen, O. (1993) Treatment of Spontaneous Intracerebral and Intracerebellar Hemorrhages. Stroke, 24, I94-95, I107-108.

[10] Weisscher, N., Vermeulen, M., Roos, Y.B. and de Haan, R.J. (2008) What Should Be Defined as Good Outcome in Stroke Trials; a Modified Rankin Score of 0-1 or 0-2? Journal of Neurology, 255, 867-874. http://dx.doi.org/10.1007/s00415-008-0796-8

[11] Vermeer, S.E., Algra, A., Franke, C.L., Koudstaal, P.J. and Rinkel, G.J. (2002) Long-Term Prognosis after Recovery from Primary Intracerebral Hemorrhage. Neurology, 59, 205-209. http://dx.doi.org/10.1212/WNL.59.2.205

[12] Broderick, J., Connolly, S., Feldmann, E., Hanley, D., Kase, C., Krieger, D., et al. (2007) Guidelines for the Management of Spontaneous Intracerebral Hemorrhage in Adults: 2007 Update: A Guideline from the American Heart Association/American Stroke Association Stroke Council, High Blood Pressure Research Council, and the Quality of Care and Outcomes in Research Interdisciplinary Working Group. Stroke, 38, 2001-2023. http://dx.doi.org/10.1161/STROKEAHA.107.183689

[13] St. Louis, E.K., Wijdicks, E. and Li, H. (1998) Predicting Neurologic Deterioration in Patients with Cerebellar Hematomas. Neurology, 51, 1364-1369. http://dx.doi.org/10.1212/WNL.51.5.1364

[14] St. Louis, E.K., Wijdicks, E.F.M., Li, H. and Atkinson, J.D. (2000) Predictors of Poor Outcome in Patients with a Spontaneous Cerebellar Hematoma. Canadian Journal of Neurological Sciences, 27, 32-36.

[15] Schwarz, S., Häfner, K., Aschoff, A. and Schwab, S. (2000) Incidence and Prognostic Significance of Fever Following Intracerebral Hemorrhage. Neurology, 54, 354-361. http://dx.doi.org/10.1212/WNL.54.2.354

[16] Chobanian, A.V., Bakris, G.L., Black, H.R., Cushman, W.C., Green, L.A., Izzo Jr., J.L., et al. (2003) The Seventh Report of the Joint National Committee on Prevention, Detection, Evaluation, and Treatment of High Blood Pressure. JAMA, 289, 2560-2572. http://dx.doi.org/10.1001/jama.289.19.2560

[17] Hårdemark, H.-G., Wesslen, N. and Persson, L. (1999) Influence of Clinical Factors, CT Findings and Early Management on Outcome in Supratentorial Intracerebral Hemorrhage. Cerebrovascular Diseases, 9, 10-21. http://dx.doi.org/10.1159/000015890

[18] Wu, Y.T., Li, T.Y., Chiang, S.L., Chu, H.Y., Chang, S.T. and Chen, L.C. (2013) Predictors of First-Week Mortality in Patients with Acute Spontaneous Cerebellar Hemorrhage. Cerebellum, 12, 165-170. http://dx.doi.org/10.1007/s12311-012-0410-6

[19] Mezzadri, J.J., Otero, J.M. and Ottino, C.A. (1993) Management of 50 Spontaneous Cerebellar Haemorrhages: Importance of Obstructive Hydrocephalus. Acta Neurochirurgica (Wien), 122, 39-44. http://dx.doi.org/10.1007/BF01446984 